\title{
COMMONSENSE ASPECTS OF BUYING AND SELLING
}

\author{
VAROL AKMAN \\ Department of Computer Engineering and Information \\ Science, Bilkent University, Bilkent, Ankara, Turkey
}

MURAT ERSAN

Department of Computer Science, Brown University, Providence, Rhode Island, USA

\begin{abstract}
We describe an experimental approach toward implementing a commonsense "microthe ory" for buying and selling. Our prototype system characterizes how intelligent agents hold items and money, how they buy and sell items, and the way money and items are transferred. The ontology of the system includes money (cash, check, credit card), agents (people, organizations), items (movable, real estate, service), barter, and the notions of transfer, loan, buying by installments, profit, and loss.
\end{abstract}

Some years since, Mademoiselle Z'elie, a singer of the Thêatre Lyrique at Paris, made a professional tour round the world, and gave a concert in the Society Islands. In exchange for an air from Norma and a few other songs, she was to receive a third part of the

We thank David Davenport (Bilkent University) for his perceptive remarks on a previous version of the manuscript. Akman's research is supported in part by a grant from the NATO Science for Stability Programme III. Sun Workstation is a registered trademark of Sun Microsystems, Inc. KEE (Knowledge Engineering Environment) is a trademark of IntelliCorp, Inc.

Address correspondence to Varol Akman, Department of Computer Engineering and Information Science, Bilkent University, Bilkent, Ankara 06533, Turkey. E-mail: akman@bilkent.edu.tr.

Cybernetics and Systems: An International Journal, 27:327-352, 1996

Copyright $\odot 1996$ Taylor \& Francis 
receipts. When counted, her share was found to consist of three pigs, twenty-three turkeys, forty-four chickens, five thousand cocoa-nuts, besides considerable quantities of bananas, lemons and oranges. At the Halle in Paris, as the prima donna remarks in her lively letter, printed by M. Wolowski, this amount of livestock and vegetables might have brought four thousand francs, which would have been good remuneration for five songs. In the Society Islands, however, pieces of money were very scarce; and as Mademoiselle could not consume any considerable portion of the receipts herself, it became necessary in the meantime to feed the pigs and poultry with the fruit.

Whereas in modern civilized society inconveniences of the above sort (Jevons, 1973, p. 25) are not really felt, ${ }^{1}$ the conventional wisdoms of buying and selling remain to be fully articulated. Having intuitively perceived the function of money, we still need to order our perceptions precisely into a logical framework. It should be remarked that Schank's conceptual dependency theory (Schank \& Abelson, 1977) and later work of his (Schank, 1980) concern representing and drawing inferences about the transfer of abstract relationships such as possession, ownership, and control-relationships of obvious concern to buying and selling. Other related works in this regard include application systems such as ATRANS 『Lytinen, 1986), which processes money transfer messages, and OpEd (Alvarado, 1990, 1992), which understands arguments in editorial texts concerning trade relationships, economic protectionism, and so on. In the areas of financial expert systems and expert systems in business (Barrett \& Beere, 1988), there are similar applications (e.g., Lassez et al., 1987), which need detailed representations of commonsense knowledge of buying and selling.

Despite all these groundbreaking, original studies, we are not aware of studies of eliciting the commonsense knowledge necessary to solve

${ }^{1}$ A colleague remarked that the problem of Mademoiselle Z'elie is not unlike the proble $m$ of having an internal currency (only traded with a country) and an external currency (traded against other currencies). He then added that this is the case in China and would be a good example. 
the simple (daily) problems of economic transactions such as buying and selling. It is true that a good place to look for information about the kind of knowledge involved in simple (micro)economics is an introductory textbook on the subject (e.g., Froyen \& Greer, 1989). Superficially, such texts appear to summarize the kinds of knowledge required to a sufficient degree, and it may be thought that formalizing that knowledge would be rather easy. A close examination, however, reveals that this is but an illusion. In all beginning economics books there is an implicit assumption on the authors' part that the reader has an existing commonsense framework. This "pre-economics" knowledge forms the background with which the newly described pieces of knowledge can be understood. SSimilar remarks have been made in the context of a pioneering study by de Kleer on naive physical reasoning (de Kleer, 1975).]

We hope to contribute to such a study here and present a commonsense microtheory ${ }^{2}$ for buying and selling and its implementation. The commonsense knowledge of events involved in this activity is formalized. Our theory describes how intelligent agents hold items and money. When an agent decides to buy or sell an item, the theory generates the resulting events, such as the transfer of an item from a seller to a buyer and the corresponding transfer of money from a buyer to a seller. The system has some portion of the naive knowledge that an agent living in a Western country in the 1990s should have in order to understand the issues involved in a buying and selling process. The ontology incorporates money (cash, check, credit card), agents (people or organizations), items (movable, real estate, service), shops, barter, and the notions of transfer, loan, buying by installments, profit, and loss.

It should be noted, however, that we have not built an expert system that is making decisions and assisting humans in business problems, like those used in credit evaluation, investment planning, or risk

${ }^{2}$ The term microtheory is borrowe $\mathrm{d}$ from Cyc, where it is used to refer to a special class of contexts (Lenat \& Guha, 1989). Different microtheories make different assumptions (and different simplifications) about the world. Contexts provide a mechanism for recording and reasoning with these assumptions. For any given topic, such as buying and selling, there may be different microtheories of that topic, at varying levels of detail and generality. 
assessment (Barrett \& Beere, 1988). These are the tasks of an "expert" on a specific topic. We are trying to formalize basic commonsense issues that every "ordinary" individual is involved in and has intuitions about.

In the first version of this paper (Ersan et al., 1993), there were several simplifying assumptions. Events involving time such as inflation and interest were not covered. In the current formalization, they are introduced but still are not completely covered. Previously, it was assumed that the buying and selling process is performed only using money. The exchange of items without using money (i.e., barter) was not taken into consideration. Now, the theory completely covers barter. It is possible to generate the events that take place in a bartering situation. New notions are also introduced into the system; for example, it handles the borrowing of money and can compute the profit and loss of the sellers. Given an inflation rate, the system is able to deduce the number and amount of installments, if the buying is being realized in installments. Also, the seller's willingness to sell items is taken into consideration. It is taken for granted that every agent accepts cash and check and that every shop accepts every kind of credit card. Different currency units can be used in buying and selling.

The essential motivation for this work comes form the Cyc project (Lenat \& Guha, 1989). We have especially been influenced by Cyc-related work by Pratt and Pratt (1991) on naive theories of money. These are microtheories that describe the ways in which agents store and transfer money. A particular microtheory focuses on the documents that are used to transfer money, the accounts that can store money, the special case of cash, and various money transfer actions. However, the theory does not cover situations in which money is used, such as buying an item. In that sense, our theory covers all these aspects and several others. We were mainly influenced by the idea of formalizing commonsense notions and the way it is done in Cyc. Pratt and Pratt's overview is rather parenthetic (after all it is only five pages long), and as we have no access to the more recent (but classified) Cyc documents, we cannot hope to evaluate the current abilities of Cyc vis-a-vis our naive economics. However, we can probably hope that our present system does incorporate many of the capabilities cited in Pratt and Pratt (1991).

We must emphasize that our aim was not to build a commercial product but to test the feasibility of such a task. Other factors that helped formulate our framework include Hayes' pioneering method- 
ological studies of naive physics (Hayes, 1979, 1985) and the general advice of McCarthy ${ }^{3}$ regarding basic research in AI (McCarthy, 1990).

The implementation of the theory has been performed on a Sun workstation using KEE (Knowledge Engineering Environment) (KEE, 1993). However, we do not want the main value of this paper to be seen as an application of KEE software in modeling the behavior of individuals in an economic system that allows for many choice variables and many exogenous influences. Although potentially this sort of modeling could be useful in a number of real-world applications (e.g., modeling of financial markets, valuation of investment assets), the main goal of our research is to understand the commonsense expectations about buying and selling. As a result, several simplifying assumptions have been made in the theory, too many, as a matter of fact, to leave a potential reader with an uncomfortable feeling about gaps and brittleness. Unfortunately, this seems to be a major problem with research in commonsense reasoning in general. True, some-if not a majority-of the system rules to be presented in the sequel will seem ad hoc. There is some difficulty in imagining the system scaling up. At this stage, we cannot really comfort the reader with such problems in mind. ${ }^{4}$ Let us simply reiterate that we believe that what we are doing here is experimental computer science, with no pretensions to be used as the basis of a practical reasoning system or a natural language system.

\section{BUYING AND SELLING}

\section{Money in Buying and Selling}

Money is a key instrument in buying and selling. Agents can hold money in different forms. They can have cash, and today this is still the

${ }^{3}$ McCarthy states that (1990, p. 188) "[w]e need good problem domains-the AI analog of what Drosophila did for genetics." We believe that buying and selling is a good proble $\mathrm{m}$ domain in this regard. First, it is full of fundamental questions - some of which we hope to tackle in the present paper-and open problems and long-term research issues. Second, this is a domain in which to make experiments that are really informative. To quote McCarthy again [15, p. 188], "[a]t present the failures are more important than (1990, p. 188), the successes, because they often tell us that the intellectual mechanisms we imagined would intelligently solve certain proble ms are inadequate."

${ }^{4}$ Maybe it may help to note that a recent Cyc newsletter states that "[ $t$ ]he entire technical approach... [upon which a project such as Cyc is based] is innovative and risky. Fortunately, over the past [eight] years the project has progressed to the point where the 'risk' is now small." 
most common way. They can have bank accounts and credit cards. There are several other ways. However, these three are the most common ones and our theory covers only these. The thing all the items used as money have in common is their acceptance (in a particular historical context) in return for other goods and services with the understanding that others would likewise accept them.

Cash can be used physically. In order to use the money in a bank account, checks are used. Agents can use as much money as they have in their bank accounts. In the case of credit cards, agents have a card and a related account with a limit. They can spend an amount of money not exceeding this limit. When they spend some money using a credit card, they owe that money to the account and should pay it back later.

Each agent in our system has an amount of money that he can spend in a buying and selling process. This amount is the sum of an agent's whole money, either in cash, bank account, or credit. The value of an agent's belongings (car, house, etc.) and the amount of the agent's spendable money total another amount called the assets of an agent. This information about an agent should be known by the system, because an agent who wants to buy something must have enough money to do so. If the item that the agent wants to buy is real estate, the spendable money might not be enough to buy it. But the agent might have other real estate and can sell the latter and use this money to buy the former.

\section{Items in Buying and Selling}

In every buying and selling process an item is involved. In our theory, everything that can be bought and sold is considered as an item. Actually, there are three different kinds ${ }^{5}$ of items: movable, real estate, and service. Our theory treats getting a service (such as a haircut or dry cleaning) as a buying and selling process; that is, an agent simply buys a service from another agent who sells this service. Items are also classified as durables and nondurables, transferable and nontransferable goods. Those that are durable have an expected lifetime and an age

${ }^{5}$ This seems quite arbitrary, and there must be more and different kinds of items. For example, bonds and stock change ownership, but their posse ssion does not essentially change because they are still held centrally in a bank. In our preliminary theory we did not treat this issue in detail because of the number of technicalities involved. 
using which we can calculate their depreciation. With the latter classification, it is seen that a service can be thought of as a nondurable and nontransferable good.

Each item in the system has an owner. This owner can be a shopkeeper or an ordinary person. Both of them can sell the items that they own. There are different kinds of shops. Agents have some commonsense knowledge about where the ordinary items of daily life are sold. ${ }^{6}$ (For example, bread and newspapers are sold at the corner store.) The values of these items are also within the commonsense knowledge of agents. If an agent has enough money and knows where to buy the item, he can buy it.

The ownership of items depends on the kind of items. If an item is movable, the owner holds the item physically. If an item is real estate, there are documents about the item and the person who holds these documents owns the item. If the item is a service, a process (receiving service) is involved and no one can hold this item physically.

Theoretically, there seems no reason why "shares" of goods could not be easily incorporated in our framework. Although our system currently does not support this, a reasonable approach would be to define $y(x, n)$ as 1 unit of a good that is itself an $n$th share in $x$, a shared good.

\section{Transfers in Buying and Selling}

One of the essential aspects of our theory of buying and selling is the idea of a transfer. The theory considers buying and selling as a money transfer and a corresponding item transfer, where the former stands for paying the value of the item and the latter stands for changing the ownership of the item.

For all these transfers to occur, some preconditions regarding the buyer and seller should hold. The buyer must have enough money and know where the item is sold, and the seller should be willing to sell that

${ }^{6}$ There is a problem here that does not go away when the individuals know the location of all the stores but not the prices at each store. Normally, individuals have to face a trade-off between accepting the price of a particular seller or incurring further search costs in the hope of finding a lower price (or a better brand, or a close substitute, etc.) elsewhere. Unfortunately, searching is known to be a costly activity in general. We admit that it would make our system much more interesting, but we did not addre ss the idea that agents are engaged in a searching activity. 
item. In our theory we assume that all shopkeepers are willing to sell the items in their shops. In fact, shops exist to sell items. On the other hand, an ordinary seller who is not a shopkeeper should agree to sell the item before the money and item transfers take place.

As the system defines money in three different types (cash, check, and credit card), the transfer of money is also categorized into three different classes. Cash transfer is the most common one. One assumption of the system is that money transfers of less than some some fixed amount are made in cash. No one (with a right mind) would use check or credit cards to buy newspapers or bread. When cash is used in buying and selling, the amount of money that an agent owns directly increases or decreases according to this role (seller or buyer).

To use a check or a credit card, an agent should have a bank or, say, a Visa account. If an agent buys an item by writing a check, the balance of his bank account would decrease by the amount transferred. On the other hand, if a credit card is used, then the amount that the agent owes to the Visa account increases. Therefore, these accounts may have negative balances. It should be kept in mind that an agent who buys an item from another agent who is not a shopkeeper cannot use his credit card but pays either in cash or by check. It is not usually possible to buy a house or your neighbor's car using your credit card.

Each money transfer has an amount and changes the amount of the spendable money of the agents. So buying an item decreases the amount of spendable money of the buyer by the amount transferred. Another important fact is that a money transfer does not always occur with a corresponding item transfer. In some cases an additional money transfer occurs when the seller gives change back to the buyer. The amount of the extra money transfer can be calculated by subtracting the value of the item from the amount of the money transfer. This "payback money transfer" occurs only when cash is used in the money transfer. The theory allows the money transfers to be in any currency unit; so an agent who gives Dutch guilders can be paid back in U.S. dollars if he wants.

The main idea behind an item transfer is the change of the ownership of an item. Here, we should remember that services are also considered to be items and are handled in a special way. After an item transfer occurs, the new owner of the item is the buyer, unless the item is a service. The way an item is transferred depends on the type of item. The transfer of a movable item (e.g., a newspaper) is performed by 
"giving" the item to the buyer. If the item is a service, then the seller gives service to the buyer (by cutting the buyer's hair, for example). The transfer of real estate, on the other hand, is considered as a transfer of a document of ownership or authorization and affects the net assets of agents. If an agent buys real estate, this results in an increase in the assets of the agent, and the seller's amount of assets decreases by the amount of that real estate.

Schank and Abelson (1977) introduced and investigated a universal knowledge representation system in which they introduced the term atrans, which stands for the transfer of an abstract relationship such as possession, ownership, or control. It is noted that Schank and Abelson's general aim was also to model common sense (1977, p. 4):

Our focus will be upon the world of psychological and physical events occupying the mental life of ordinary individuals. Our knowledge systems will embody what has been called 'naive psychology' [...]-the common sense (though perhaps wrong) assumptions which people make about the motives and behavior of themselves and others - and also a kind of 'naive physics', or primitive intuition, as is captured in Conceptual Dependency (CD) theory.

In our theory both the transfer of money and that of items can be considered as atrans. However, we believe that a commonsense microtheory should be more fine-grained than this approach. For example, in Schank and Abelson's pragmatic approach the transfer of the ownership of money must simply be considered as an atrans of money. Yet, in our system we further categorize this transfer of money into three different classes because there are different rules dealing with different classes. The same argument holds for the transfer of items.

The following scenario is given to elucidate how the system performs a buying and selling process. Each KEE figure represents a unit. Each unit has a number of slots, and each slot has a certain value of a certain value class. The values of a unit may be inherited from another unit (indicated as From Unit in the figures) according to the inheritance type (indicated as Inheritance in the figures). John is an agent in the system (Figure 1a). He wants to buy a newspaper (Figure 1b). His goal is given to the system using the structure in Figure 1c. Given only this information, the system tries to perform the buying and selling process. First, the system checks whether John has enough money to buy a 


\begin{tabular}{|c|c|c|c|c|}
\hline |ll (Output) & List of th & Unit in the S & PIrJG Kuowledge Base & \\
\hline Slot & & Inheritance & Value Class & \\
\hline 0: ASSETS & (15000) & & $\begin{array}{l}\text { OVERAIDE.VALUES } \\
\text { (INTEGER) }\end{array}$ & JOHN \\
\hline D: LOAN & (0) & & $\begin{array}{l}\text { OVERRIDE.VALUES } \\
\text { (INTEGER) }\end{array}$ & JOHN \\
\hline p: SPENDA & $\begin{array}{l}\text { MONEY } \\
\text { (1000) }\end{array}$ & & $\begin{array}{l}\text { OVERRIDE.VALUES } \\
\text { (INTEGER) }\end{array}$ & JOHN \\
\hline
\end{tabular}

Figure 1(a). The unit representing John, an agent. It keeps the amounts of John's asse ts, loans, and spendable money. All of these slots are of integer type. They all have certain values none of which is inherited.

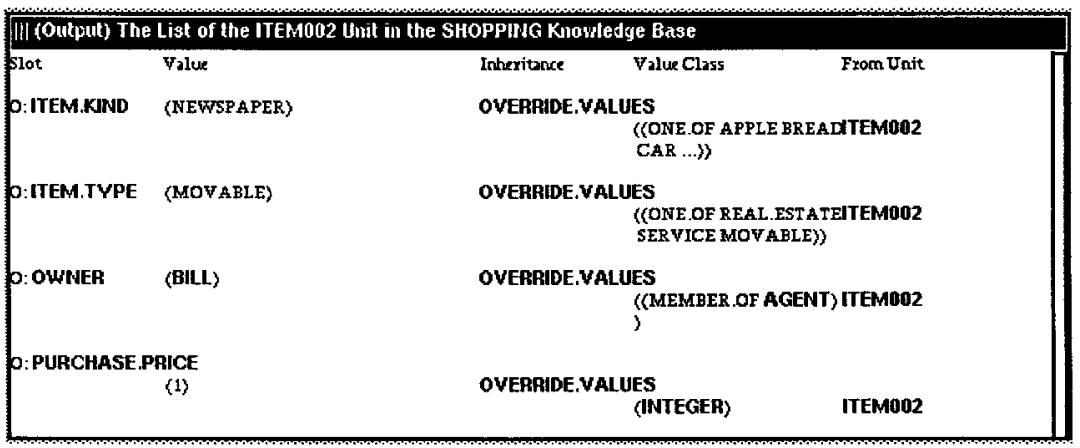

Figure 1(b). The unit representing the newspaper.

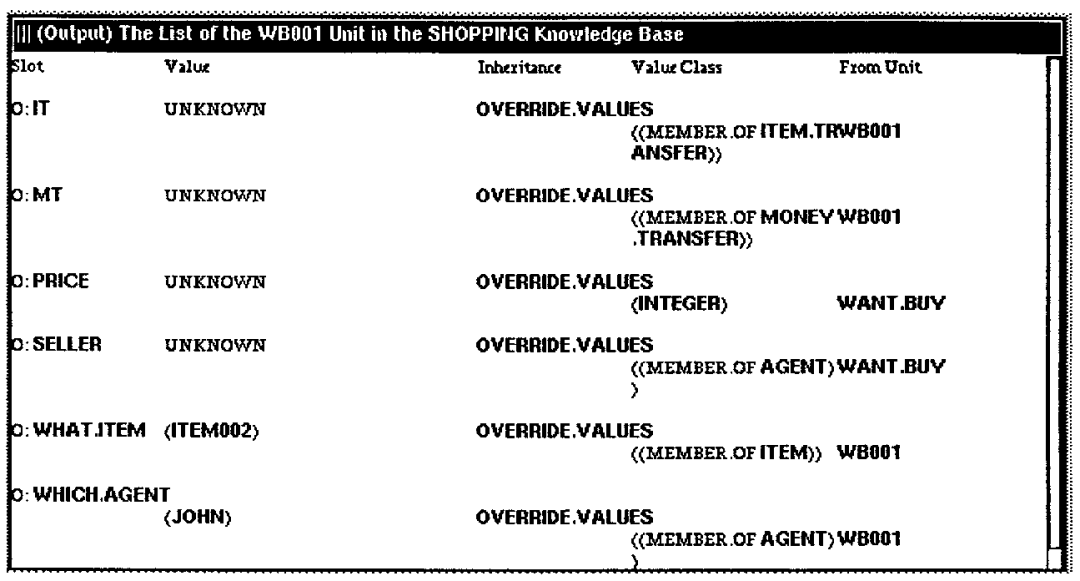

Figure 1( c). The unit representing John's goal of buying a newspaper. 


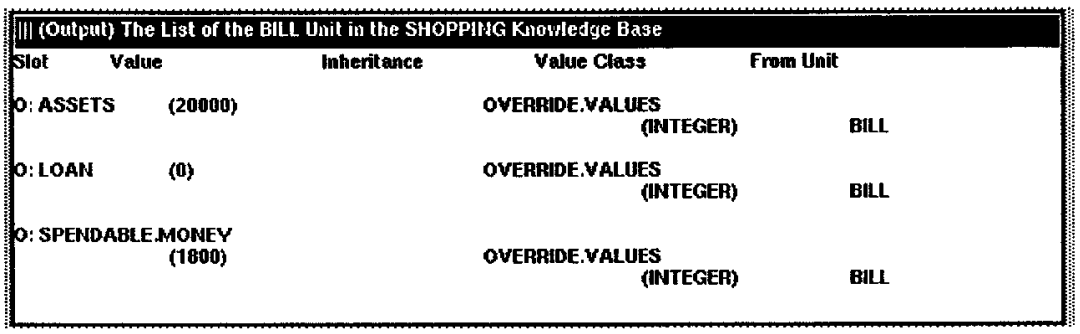

Figure 1(d). The unit representing Bill, another agent.

newspaper. Although the price and the seller of the newspaper are not given explicitly, the system has the commonsense knowledge of what the price of a newspaper is and where it is sold. In the system, Bill is the proprietor of the corner store where the newspapers are sold (Figure 1d). Finding out that John has enough money and the (current) owner of the newspaper is Bill, the system generates an item transfer (Figure 1e) from Bill to John and a money transfer (Figure 1f) from John to Bill. It deduces the commonsense knowledge that when a newspaper is sold the ownership changes by giving the item physically. Similarly, it deduces that the payment is made in cash and no payback will occur because it is not stated that John has paid an excess amount of money to Bill. After the buying and selling process is over, Bill's spendable money has increased (Figure 1g) and John's has decreased (Figure 1h). The new owner of the item is John (Figure 1i).

\begin{tabular}{|c|c|}
\hline \multicolumn{2}{|c|}{ III (Outpul) The List of the it208 Unit in the SHOPPIPG Knouledge Base } \\
\hline Value & Value Class \\
\hline $\begin{array}{l}\text { P:FROM.LOCATION } \\
\text { (BILL) }\end{array}$ & $\begin{array}{l}\text { OVERRIDE.VALUES } \\
\qquad \text { (MEMBER OF AGENT) it208 }\end{array}$ \\
\hline $\begin{array}{l}\text { P:ITEM.THANSFER.MODE } \\
\text { (GIVING.ITEM) }\end{array}$ & $\begin{array}{l}\text { OVERAIDE.VALUES } \\
\qquad \begin{array}{l}\text { ((ONE, OF GIVING.ITEMIL208 } \\
\text { GIVING.DOCUMENT GI } \\
\text { VING SER VICE)) }\end{array}\end{array}$ \\
\hline $\begin{array}{l}\text { O:ITEM.TRANSFERRED } \\
\text { (ITEM002) }\end{array}$ & $\begin{array}{l}\text { OVERAIDE.VALUES } \\
\qquad \text { ((MEMBER OF ITEM)) it208 }\end{array}$ \\
\hline O:TO.LOCATION & 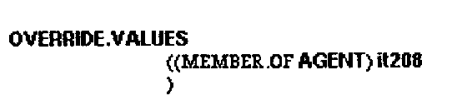 \\
\hline
\end{tabular}

Figure 1(e). The transfer of the newspaper from Bill to John. 


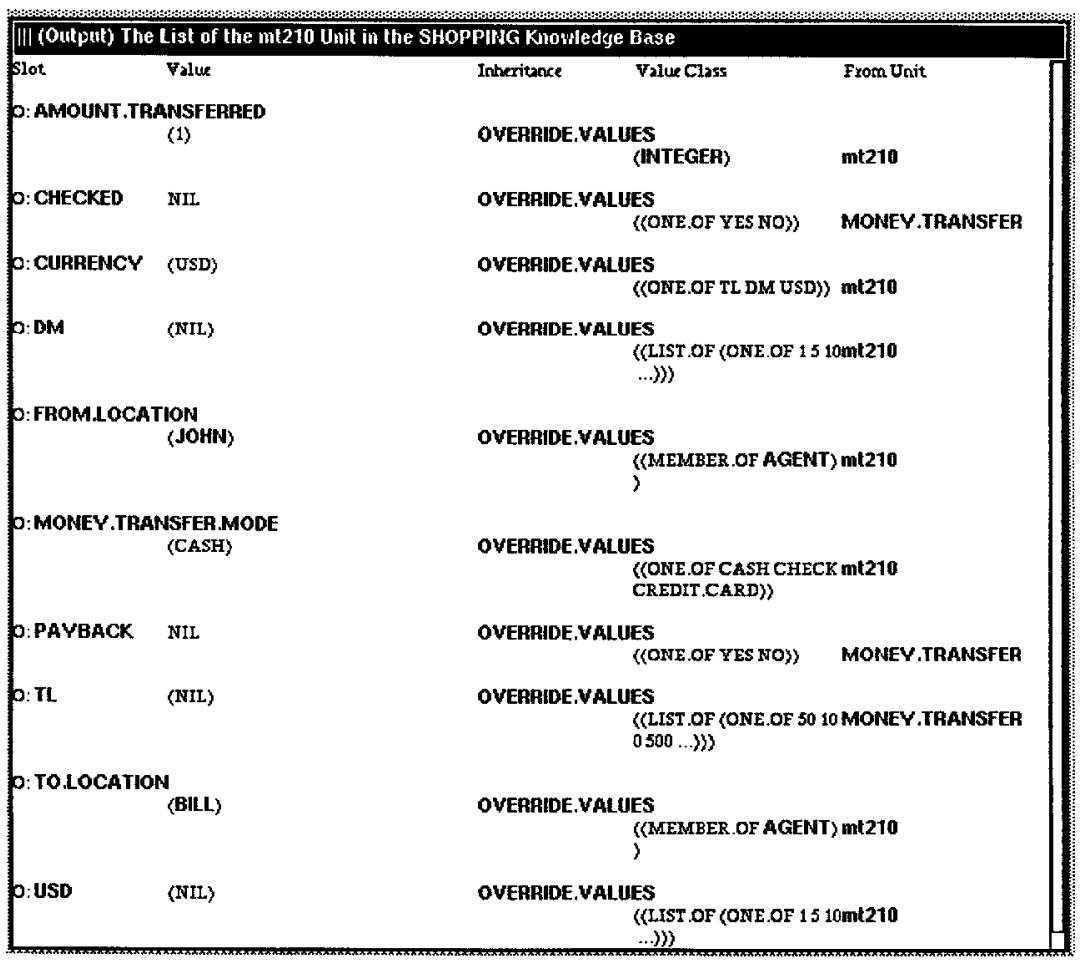

Figure 1( $\boldsymbol{f})$. The transfer of money from John to Bill.

\section{Profit and Loss in Buying and Selling}

In general, selling processes are profit oriented. A seller's, especially a shopkeeper's, main aim is to make profit. Nobody wants to sell an item to lose money. But there are some exceptions. The seller may need

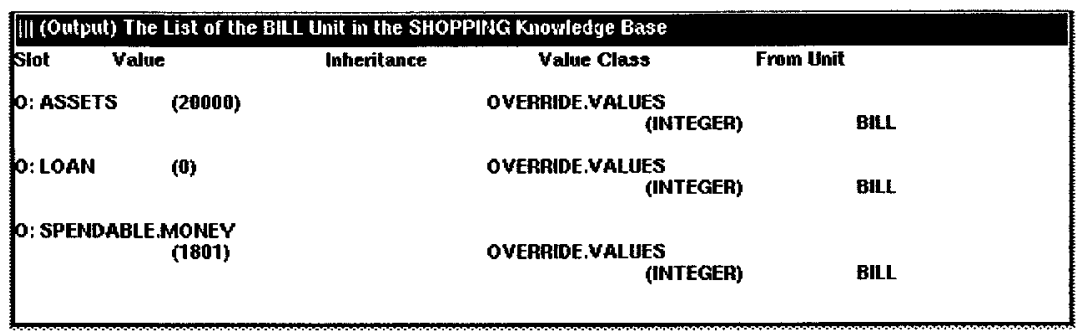

Figure 1( g). The unit representing Bill after the process is over. 


\begin{tabular}{|c|c|c|c|c|}
\hline \multicolumn{5}{|c|}{ |il (Outpul) The List of the JOHP Unit in the SHOPPIRJG Krowledge Base } \\
\hline \multicolumn{2}{|c|}{ Slot Value } & \multirow[t]{2}{*}{ Inheritance } & Value Class & From Unit \\
\hline 0: ASSETS & (15080) & & $\begin{array}{l}\text { OVERRIDE.VALUES } \\
\text { (INTEGER) }\end{array}$ & JOHN \\
\hline 0: LOAN & (0) & & $\begin{array}{l}\text { OVERRIDE, VALUES } \\
\text { (INTEGER) }\end{array}$ & JOHN \\
\hline \multicolumn{3}{|c|}{$\begin{array}{c}\text { O: SPENDABLE.MONEY } \\
\text { (999) }\end{array}$} & $\begin{array}{l}\text { OVERRIDE.VALUES } \\
\text { (INTEGER) }\end{array}$ & JOHN \\
\hline
\end{tabular}

Figure 1( h). The unit representing John after the process is over.

some amount of money urgently. In this case, he sells an item without considering profit. In another case, the seller knows or strongly guesses that if he does not sell a particular kind of item with a little loss, he will not be able to sell it in the future at all. Therefore, he can accept to lose some money. Also, in some cases, sellers sell an item with loss deliberately because they expect other kinds of profit from this selling process. The profit may be in cash or in some other form (e.g., to make some other seller lose money or even to make someone go bankrupt).

Items have two types of price: purchase price and sale price. In a buying and selling process, if the sale price of the item involved is greater than the purchase price of the item, the seller makes a profit. The amount of profit is the difference of two prices of the item. If the sale price is less than the purchase price, this indicates a loss for the seller. After the buying and selling process is performed, the purchase price of the item is changed to the sale price. If the new owner of the item wants to do so, he can determine the new sale price of the item.

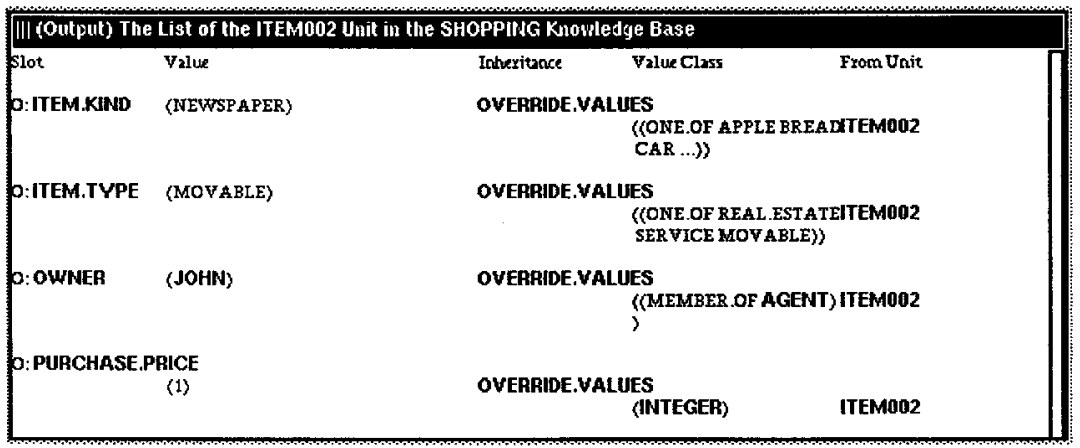

Figure 1(i). The unit representing the newspaper after the process is over. 
While determining the new sale price, the owner of the item knows that, in general, the sale price of the item should not be much more (or less) than the market price of that item.

The system also takes into account the depreciation of the goods (especially for second-hand goods) and the inflation rate when calculating the profit and loss. Depreciation is the loss in value due to physical deterioration (wear and tear) as well as the obsolescence of a durable good. It is also considered as the cost of owning an asset for, say, a year. Among a variety of depreciation methods based on the price of the durable good, the most common one is straight-line depreciation. According to this method, the same fraction of the original price is charged to current costs each year of the expected useful life of the durable good. So if one buys a used car for $\$ 600$ and expects to use it for 6 years, then at the end of each year he should deduct $\$ 100$ dollars from the price. As a result, if he sells his car for $\$ 450$ at the end of the second year, it should not be considered as a loss, but a profit of $\$ 50 .^{7}$

The theory does not cover the notion of profit and loss of the buyer, which might occur when an agent buys an item for a higher (or lower) price than the market price. However, if an agent has alternatives, he prefers to buy an item from the seller who sells the same item for a lower price. Similarly, a seller prefers to sell his items to the agent who makes the best offer.

\section{Buying in Installments}

In a buying and selling process, if the seller and buyer agree, the buyer does not have to pay the whole price of the item immediately. The seller and the buyer can agree on a payment plan according to which the buyer pays the price of the item in portions at predefined dates. This is known as buying in installments. This kind of buying can occur when the price of the item involved is more than a certain amount. This amount changes according to the time and place, but it is common knowledge that nobody buys bread in installments. Only if the price of the item is

${ }^{7}$ Similarly, assume that a shopkeeper buys a camera for $\$ 100$, keeps it in stock for a year, and then sells it for $\$ 105$. The shopkeeper would not have made any profit, if the inflation rate turns out to be higher than $5 \%$. 
high enough to buy it in installments might buyers prefer this kind of buying.

Here, agreement of the seller and the buyer is the most important point. The amount of the installments and the dates when they will be honored are decided. These are usually different for different sellers and buyers at different times. A seller may want some kind of assurance from a buyer that the buyer is able to pay that amount of money. For example, if the buyer has some documents indicating that he has a regular salary, then the seller might be convinced. In general, the agreement is not verbal; some documents are prepared and signed by both the buyer and the seller. Therefore, the buyer has to pay all the installments in time. If he does not, the seller has the right to sue the buyer (or to repossess the sold item). Similar considerations apply to the seller; specifically, he has to give the item to the buyer in time. Usually the buyer pays a certain amount of the item's price in advance and the rest of the money is divided into (equal) payments. When the buyer is willing to pay more in advance, the portions become smaller in amount or in number. ${ }^{8}$

Depending on the agreement reached between the buyer and seller, the buyer receives the item either after the agreement is made or after all of the installments are paid. Other conditions being equal, buyers would usually prefer the former option.

\section{Loan}

An important process in economic life is the borrowing of money and items. It can be defined as taking or receiving something for a certain time, intending to return it. If an agent borrows an item, he can use it for a time period. The important point is that only the user of the item changes, the owner of the item does not. Sometimes, people borrow items from their friends and do not pay anything in return (except, probably, a word of thanks). If an agent borrows an item from a shop

${ }^{8}$ While deciding the amount of installments, the rate of inflation should be taken into consideration. The total amount of money that the seller will get should be high enough to compensate for the loss arising from inflation. Thus, the price of the item is augmented by an amount according to the current annual inflation rate and then divided into portions. If the inflation rate is $I$, price of the item is $P$, amount paid in advance is $A$, and number of installments is $M$, then the amount of installments should be at least $P(((I M / 12)+1)-A) / M$. 
(i.e, renting), he should pay for it. These concepts are not covered in this theory. We will mainly deal with lending and borrowing money. So we can consider a loan as a way agents increase their spendable money for a certain time period.

When an agent wants to borrow money he should first find a lender. There are generally three types of lenders:

An agent who is a relative or a friend.

An agent whose profession is legally to lend money, such as a bank.

An agent who illegally lends money, such as a usurer.

The borrower should return the money in a certain amount of time either by paying the whole amount or by paying by installments. This usually depends on who the lender is.

If the lender is a friend, the amount to be borrowed cannot be more than a certain amount, which is generally proportional to the wealth of the lender. Depending on the amount borrowed and the pay date, either no or low interest will be paid.

If the lender is an agent whose reason for existence is lending money, such as a bank, the borrower must have some assurance to offer the bank. The amount of money the bank will lend is proportional to this assurance. In addition to the assurance, the borrower should not have any serious debts to other agents in order to borrow money from a bank. There is always some interest involved, and the pay dates are strict. If the loan is not paid back on time, the agent may be charged some more money or the bank may seize the items that were offered as an assurance.

If the agent borrows money from an usurer, the interest rate is generally higher than that of the bank. Some usurers do not need an assurance, but if the money is not returned on time the borrower might be in trouble in countless ways.

\section{Barter}

In our preliminary study of the ontology (Ersan et al., 1993), we dealt only with buying and selling performed using money. This should not be considered the only way to obtain an item, as the illustration preceding this paper shows. Barter is an alternative for the same process. It is defined as the direct exchange of items of equal value without the use 
of currency. In fact, in times when money did not exist barter was the only way to obtain items. The bartering process starts when an agent wants a specific item and has some other items to offer for this item. Another agent who owns the specific item and is willing to exchange it with the offered items should also exist. The process ends with the exchange of items and can be considered as consisting of two item transfers.

The important aspect of barter is a desire to exchange. How do agents decide that two items may be exchanged? One answer would be that this depends on the values of items, but the term value is also intricate. Value is the ratio in which the unit of measure of one thing exchanges for a multiple, or fraction, of the unit of measure of any other determinate thing. For instance, we may say that the value of a certain kind of wheat, at a given time and place, is 30 shillings, if a quarter of such wheat is actually exchanged, at that time and place, for 30 shillings. Value, in other words, is a mathematical proportion between two quantities of wealth exchanged against one another in a given market. Agents assign values to items according to different criteria. One is the price of the item; another is the "craving" of the agent for that item. Some items, although cheap in price, may have great private value (e.g., a broken watch inherited from a grandfather). One other criterion that decides the value is the time and place in which the barter takes place. If an item is not produced or easily found in a country, its value is greater than the same kind of item's value where it is produced. As a result, value is affected by many factors such as economical, psychological, and historical factors.

The main problem with barter, and the reason it is rarely practiced, is that the agents must have a double coincidence of wants (Froyen \& Greer, 1989). Such match-ups scarcely exist in the real world. ${ }^{9}$

\section{IMPLEMENTATION}

\section{Knowledge Engineering Environment}

In the implementation of the theory, KEE is used as a software development tool (KEE, 1993). This is a knowledge system development product that provides software developers with a set of programming

${ }^{9}$ For example, to work as a McDonald's counter attendant, one would have to be willing to exchange 6 hour of daily labor services for something like six Big Macs and two Cokes per day every day! 
tools and techniques for building applications to represent and analyze knowledge.

KEE has a frame system. The basis of this system is a unit. Units are similar to frames. They represent the objects in the theory. Units contain a number of slots. Slots are used to describe the attributes of objects and can hold numerical data, text, tables, graphics, pointers to other units, and procedures written in Lisp. Units can be organized into hierarchies, enabling the knowledge base to be constructed in a more logical manner (Figure 2). Coupled with KEE's inheritance mechanism, this allows efficient storage and reasoning.

In our system commonsense knowledge is deduced using a number of rules. These rules are implemented in the Rulesystem $\llbracket$ sic of KEE. Rules, like any other data structure in KEE, are in the form of units and can be organized into classes. What the Rulesystem does is to prove the conclusions of a rule using the premises of the rule. When the premises of a rule can be shown to hold by the information in the knowledge base, the conclusions are deduced to be true. The Rulesystem supports both forward and backward chaining.

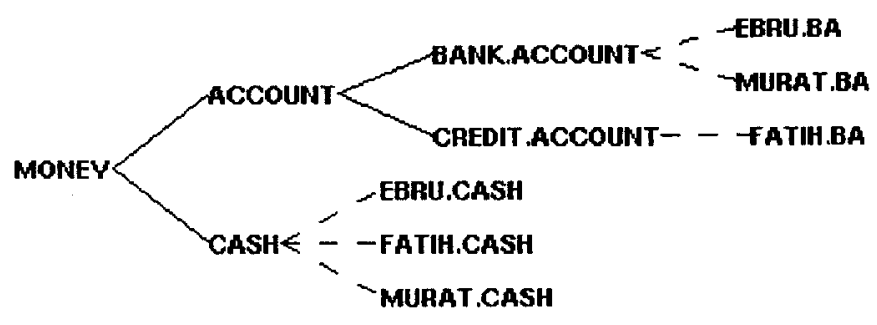

MONEY.RULES $\leqslant \frac{- \text { RULE42 }}{2}-$ RULE43
- RULE44

SHOP $\leq--$ SHOP001
- SHOP002
- SHOP003

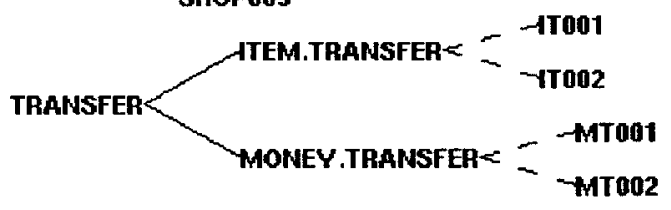

Figure 2. A sample view of the hie rarchy of some units in the system. 
As for the rules themselves, they may seem to be token rules that represent numerous similar rules that would be needed. Since we do not have thousands of such rules, we should indicate this, and provide a feeling for their coverage. The problem is that some rules are real defaults; as we treat the individual instantiations of every real-world situation, there will be a need for default reasoning (Ginsberg, 1987). There are assorted proposals in the AI literature to perform the latter and therefore we do not, in this paper, delve into the specifics of default rules.

\section{Implementation Details}

Units. There are eight main units: agent, item, money, shop, transfer, want.buy, want.borrow, and want.barter.

Agent represents the agents involved in the buying and selling process. Agents can be people or organizations. Buyers and sellers are introduced to the system as members of this unit. It has three slots: assets, loan, and spendable.money.

Item represents the item involved in the buying and selling process. There is no limit on the number and kind of items that can exist in the system. There are five slots of this unit: item.kind (bread, apple, car, house, etc.), item.type (movable, service, real estate), owner, purchase.price, sale.price, durability (durable, non.durable), life.time, and age.

Money holds the common attributes of money in different forms that an agent can have. It has two slots, holder and balance, and two subclasses, cash and account. Cash represents the money that an agent has in cash. Account represents the accounts of an agent, with an additional slot account.administrator. Bank.Account and Credit.Account are two subclasses of account. Bank.Account describes the bank account of an agent. Credit.Account describes the credit card account of an agent. It has one additional slot, limit, that indicates how much credit an agent has.

Shop represents the shops in which the buying and selling takes place. The kinds and the number of shops in the system are not limited. This unit has two slots: keeper and shop.type (pharmacy, real estate agency, etc.).

Transfer represents the transfers performed in buying and selling. It has two subclasses, item.transfer and money.transfer, and two slots that describe the common attributes of the transfers: from.location 
and to.location. Item. Transfer represents the transfer of items in buying and selling. It has two additional slots: item.transferred and item.transfer.mode. Money.Transfer represents the money transfer from buyer to seller in a buying and selling process. This unit is also used when the buyer should receive change from the seller. Its main slots are amount.transferred, money.transfer.mode (cash, check, credit card), and currency.

Want.Buy represents a demand for buying an item. When an agent wants to buy an item, this unit is used to hold the information of the buying and selling process. It has five slots: what.item, which.agent, price, seller, and profit.loss (of the seller).

Want.Borrow represents a demand for borrowing money. This is the unit used to hold the information of the borrowing process and has seven slots: borrower, amount.borrowed, lender, category (friend, bank, usurer), pay.date, interest, and assurance.

Want.Barter is the unit which holds the necessary information about a bartering process. It is used when an agent wants to exchange one of his items with another agent's item. The slots of this unit are first.agent, wanted.item, offered.item, and second.agent.

Rules. The inference mechanism of the system is provided by a number of rule classes built into the Rulesystem. To make the reasoning more efficient, the rules are grouped into classes. Depending on the type of knowledge entered, a certain rule class is triggered and new facts are added to the knowledge base. Among these rules, some can be regarded as defaults, that is, rules for default reasoning. Using these rules, it is possible to derive conclusions despite the absence of total information. Currently, the system contains four rule classes: item.rules, money.rules, want.buy.rules, and transfer.rules.

Item.Rules is triggered whenever a new item is created. It contains rules that deduce the sale price and type of each item, that is, whether it is real estate, service, or movable. These rules are defaults and are activated if the user does not provide total information. When an item is created, its owner and kind should be specified. Some of the rules (translated to English) are as follows:

If the sale price of bread is not specified, then it is a couple of dollars. If the sale price of a car is not specified, then ask the user.

If the item is a newspaper, then it is a movable item.

If the item is a haircut, then it is a service. 
There is one more rule stating that when a real estate is created, the net worth of the owner of this item is incremented by the value of that item.

Money.Rules is triggered each time a money unit is created; this can be either cash, bank.account or creditaccount. It updates the amount of the spendable money of the agent who owns this money. Some rules:

If an agent is given cash, then his spendable money increases by the amount of the cash.

If an agent is given a bank account, then his spendable money increases by the amount of the account balance.

If an agent is given a V isa account, then his spendable money increases by the amount of the limit of that account.

Want.Buy.Rules can be considered to be the heart of the system because when a buying and selling process occurs, this rule class is triggered. The agent and the item he wants to buy should be specified. The seller and the amount of money offered are optional. If these are not specified by the user, the seller is deduced using transfer.rules and the money given is assumed to be equal to the price of the item. Using the purchase and sale price of the item, the profit or loss of the seller is calculated. If the conditions for a buying and selling event are satisfied, the system creates a corresponding money transfer and an item transfer automatically. Some example rules are:

If an agent wants to buy an item from a seller and has enough money, then a money transfer from the agent to the seller and an item transfer from the seller to the agent occur (Figure 3).

If the money that the agent gives is not specified, then assume that the agent gives the exact price of the item, not more.

If the sale price of the item is greater than its purchase price, then the profit of the seller is the difference between the sale and purchase prices.

If the sale price of the item is less than its purchase price, then the loss of the seller is the difference between the sale and purchase prices.

Want.Borrow.Rules is triggered each time an agent wants to borrow an amount of money from another agent, which can be either a friend, a bank, or a usurer. The borrower and the amount of be 


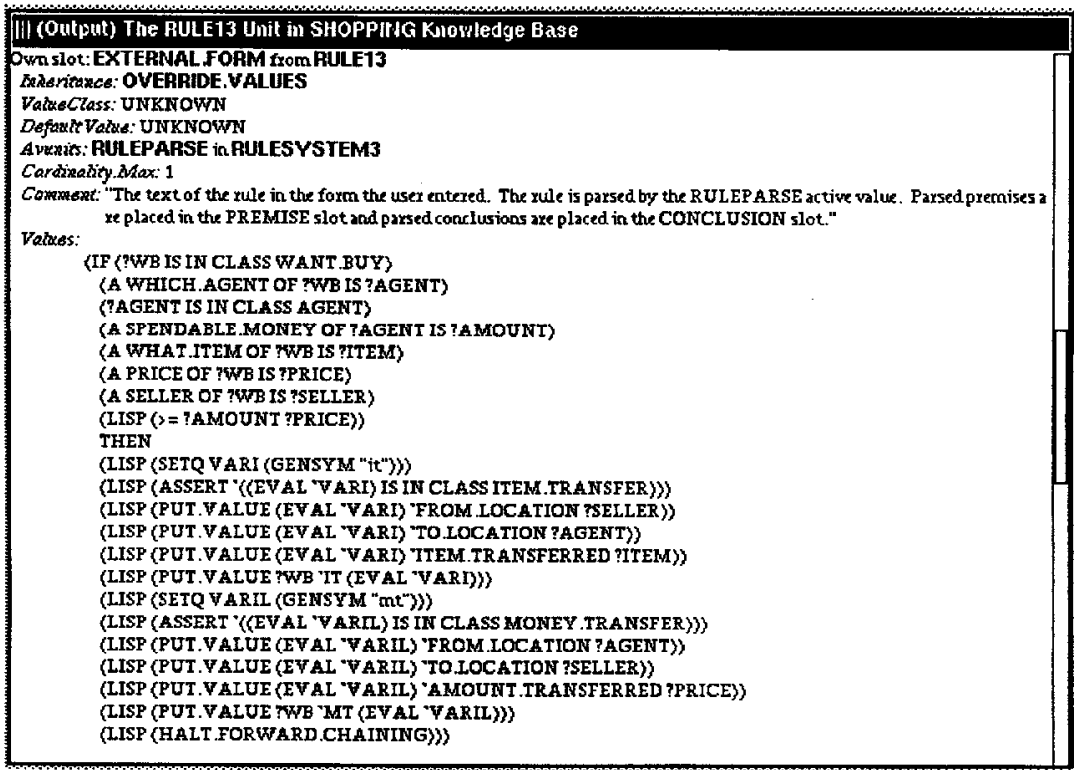

Figure 3. An example of how rules are implemented in KEE. Here, Lisp commands and the rule structure of KEE are combined. This rule is activated when an agent wants to buy an item. It is checked whether the agent has enough money and the seller is known by the system. If the premises are satisfied, the system generates an item transfer and a corresponding money transfer, filling the slots of these units with the necessary information.

borrowed must be specified. If the information about the other slots is not given, it is determined by default rules such as the following ones. If all the conditions are satisfied, a money transfer is created from the lender to the borrower. Some of the rules are:

If an agent wants to borrow some money from another agent who is willing to lend it, a money transfer from the lender to the borrower occurs.

A bank is willing to lend money only if the borrower has some assurance and little or no debt to the other agents.

The amount of money a bank will lend is proportional to the borrower's assurance.

If an agent borrows from a friend less than a couple of hundred dollars for a couple of months, no interest will be charged. 
If the lender is not specified and the amount of money to be borrowed is more than a couple of hundred dollars, then the lender is a bank.

Want.Barter.Rules is triggered whenever there is a demand for bartering. The agent who wants to barter should specify the item he wants, know the owner of that item, and offer one of his items in exchange. If the other agent accepts this offer, the barter takes place. Some of the rules in this class are:

If an agent wants to barter an item from another agent offering an item, see if the agent is willing to exchange his item with the offered one. If both agents agree on the barter, two item transfers occur.

Transfer.Rules is triggered when a money or item transfer is created by the want.buy.rules and fills the required slots of these transfers. If the seller of an item transfer has not been specified during a buying and selling process, a group in this class of rules deduces the commonsense knowledge of who the seller is. Another function of these rules is the balancing of money, bank, and, say, Visa accounts. So each time a money transfer occurs, the balance of the seller is increased while that of the buyer is decreased. This rule class also determines whether the seller will return change to the buyer. In this case a new money transfer occurs from the seller to the buyer.

The money transfer mode of the process is determined. If the money transfer mode has not been specified and the amount that is to be transferred is less than some fixed amount, then it is assumed to be a cash transfer. Otherwise, the user is asked to enter the transfer mode. The item transfer mode is determined according to the type of the item. There are rules that determine the new owner of an item after an item transfer and how the assets of an agent change when the item transferred is real estate. Some of the rules in this class are:

If not specified, then the seller of apples is the greengrocer.

If not specified, then the seller of a house is a real estate agency.

If a money transfer is made in cash, then both the amount of cash that the seller owns and the amount of his spendable money increase.

If a money transfer is made by a check, then both the balance of the buyer's bank account and the amount of his spendable money decrease. 
After an item transfer, the new owner of the item is the agent who bought it.

\section{CONCLUDING REMARKS}

This paper summarized the implementation of a preliminary model for commonsense buying and selling, following in the tradition of Cyc. We have built a preliminary microtheory for buying and selling. In this commonsense theory, the basic objects and events of buying and selling are formalized. We have covered a part of the intuitive knowledge that an agent should have in order to understand the events involved in a buying and selling process. We have implemented a system that uses this theory to represent the steps of buying and selling, the resulting situations, and the commonsense knowledge involved in these situations.

It is useful to extend the theory to cover more difficult notions like stealing, spending patterns, liquidity preference, price fixing, tax, black market, and search for the adequate price. Seemingly innocent questions such as "Is there a limit to service availability (e.g., an out-of-print book)?" or "Can an agent refuse to pay for a faulty item (e.g., a tasteless soup)?" should also be addressed. (Clearly, the answer to both questions should be in the affirmative.)

It is also possible to see a narrower scope for the program explained in this paper, that is, to show how it can help us understand how an economic system made up of many agents making many (intelligent) decisions. This would probably take us to more involved issues, but it is worth serious consideration. For example, a colleague has asked whether our program can show what happens when money is introduced into a barter economy. ${ }^{10}$

We agree that these are all interesting - and equally troublesome - questions and, at this stage, can only add that they are being actively

${ }^{10}$ Unfortunately, this is a difficult question that has more to do with simulation and game theory than knowledge representation per se. More specifically, what happens to the aggregate wealth of the individuals? What happens to the volume of trade? If production decisions are integrated into the program, do individuals become more specialized after money is introduce $\mathrm{d}$ ? 
researched by us and, we hope, by others. After all, "[d] oing this job is necessary, important, difficult, and fun" (Hayes, 1985, p. 35).

\section{REFERENCES}

Alvarado, S. J. 1990. Understanding Editorial Text: A Computer Model of Argument Comprehension. Boston: Kluwer Academic Publishers.

Alvarado, S. J. 1992. Argument comprehension. In Encyclopedia of Artificial Intelligence, ed. S. C. Shapiro, 2nd ed., 30-52. New York: Wiley.

Barrett, M. L., and A. C. Beere1. 1988. Expert Systems in Business: A Practical Approach. New York: Halsted.

de Kleer, J. 1975. Qualitative and Quantitative Knowledge in Classical Mechanics. Technical Report AI-TR-352, AI Laboratory, Massachusetts Institute of Technology, Cambridge.

Ersan, M., E. Ersan, and V. Akman. 1993. Ontology for buying and selling: A preliminary study. Proceedings of the Second Turkish Symposium on AI and Artificial Neural Networks, eds. S. Kuru et a1., Bosphorus University, Istanbul, Turkey, pp. 1-7.

Froyen, R. T. and D. F. Greer. 1989. Principles of Microeconomics. New York: Macmillan.

Ginsberg, M. L., ed. 1987. Readings in Nonomonotonic Reasoning. Los Altos, CA: Morgan Kaufmann.

Hayes, P. J. 1979. The naive physics manifesto. In Expert Systems in the Micro-Electronic Age, ed. D. Michie, 242-270. Edinburgh, UK: Edinburgh University Press.

Hayes, P. J. 1985. The second naive physics manifesto. In Formal Theories of the Commonsense World, eds. J. Hobbs and R. Moore, 1-36. Norwood, NJ: Ablex.

Jevons, W. S. 1973. Barter. In Monetary Theory: Selected Readings, ed. R. W. Clower, 25-29. Harmondsworth, Middlesex, UK: Penguin.

KEE (Knowledge Engineering Environment). 1993. Software Development System, Version 4.1, IntelliCorp Inc., Mountain View, CA.

Lassez, C., K. McAloon, and R. Yap. 1987. Constraint logic programming and option trading. IEEE Expert 2(3):42-50.

Lenat, D. B., and R. V. Guha. 1989. Building Large Knowledge-Based Systems (Representation and Inference in the Cyc Project). Reading, MA: AddisonWesley.

Lytinen, S. 1986. ATRANS: Automatic processing of money transfer messages. Proceedings of the Fifth National Conference on Artificial Intelligence (AAAI86), Philadelphia, pp. 1089-1093. 
McCarthy, J. 1990. AI needs more emphasis on basic research. In Formalizing Common Sense: Papers by John McCarthy, ed. V. Lifschitz, 187-188. Norwood, NJ: Ablex.

Pratt, D., and W. Pratt. 1991. A naive theory of money. In The World According to Cyc, Part 4, D. B. Lenat et al. (contributors). Technical Report ACTCYC-022-91, Microelectronics and Computer Technology Corporation, Austin, TX, pp. 19-24.

Schank, R. C. 1980. Language and memory. Cogn. Sci. 4:243-284.

Schank, R.C., and R. P. Abelson. 1977. Scripts, Plans, Goals, and Understanding. Hillsdale, NJ: Lawrence Erlbaum. 